American Journal of Pharmaceutical Education 2020; 84 (3) Article 847512.

\title{
COMMENTARY
}

\section{Developing Self-Directed Learners}

\author{
Jennifer D. Robinson, PharmD ${ }^{\mathrm{a}}$, Adam M. Persky, $\mathrm{PhD}^{\mathrm{b}, \mathrm{c}}$ \\ ${ }^{a}$ Washington State University College of Pharmacy and Pharmaceutical Sciences, Spokane, Washington \\ ${ }^{\mathrm{b}}$ University of North Carolina at Chapel Hill, UNC Eshelman School of Pharmacy, Chapel Hill, North Carolina \\ ${ }^{c}$ Associate Editor, American Journal of Pharmaceutical Education, Arlington, Virginia
}

Submitted January 24, 2019; accepted September 24, 2019; published March 2020.

\begin{abstract}
Objective. To discuss the meaning of self-directed learning, challenges with implementation, and strategies to overcome obstacles in educational settings. In this paper we define self-directed learning, differentiate it from similar terminology, and discuss the empirical evidence for its development and strategies for its use within higher education.

Summary. Self-directed learning as a defined teaching pedagogy has been around since the 1960s and can be used in classroom and experiential settings. It is a term that is commonly used to describe a set of skills that college graduates should possess. A self-directed learning environment is dramatically different from a lecture-based classroom where the educator determines the goals, the assessments administered, and pacing of the course content. During the self-directed learning process, the learner sets goals, determines how progress will be assessed, defines the structure and sequence of activities and a timeline, identifies resources, and seeks out feedback. When teaching individuals who are new to this model, care must be taken to appropriately scaffold and structure learning to develop the underlying soft skills needed for students to be successful as self-directed learners. When implementing this pedagogy in a classroom setting, challenges are faced both by the learner and the educator. Faculty members should proactively plan for potential challenges during the course design process.
\end{abstract}

Keywords: self-directed learning, student led learning, instructional design, self-regulation, self-paced

\section{INTRODUCTION}

The Institute of Medicine states that health-care professionals need to possess the skills associated with lifelong learning. This idea of lifelong learning is included in the Center for the Advancement of Pharmaceutical Education (CAPE) outcomes and the Accreditation Council on Pharmaceutical Education(ACPE) Standards 2016 standard 3 and 4. Becoming a lifelong learner requires health-care providers to be self-directed. Despite the popularity of this term among faculty members and accrediting bodies, there may be a lack of consensus among faculty members as to the exact definition of self-directed learning (SDL), how to implement SDL, and/or how to develop self-directed learners. ${ }^{1}$ Part of this discord may be because of the similarity in terminology with other educational terms (ie, self-paced learning or selfregulated learning). In this paper we will define SDL, differentiate it from similar terminology, and discuss the empirical evidence supporting its development within adult education.

Corresponding Author: Jennifer D. Robinson, PO Box 1495, Department of Pharmacotherapy, College of Pharmacy and Pharmaceutical Sciences, Washington State University, Spokane, WA 99210-1495. Tel: 509-368-6676. Fax: 509-3587967. Email: jenirobinson@wsu.edu.

\section{Self-Directed Learning}

Self-directed learning can be defined as the outcome of creating an experience that empowers learners to make decisions about the information they want to become proficient in. ${ }^{2}$ Self-directed learning may be seen primarily in the experiential setting, eg, when a patient presents with an unfamiliar disease state and students must find appropriate resources and learn about this information. Second, SDL may be seen in cocurricular activities as students learn about topics of interest to them. While SDL usually takes place in the experiential or co-curricular setting, the skills necessary for SDL should be introduced and developed in the didactic portion of the curriculum. This allows students to develop skills over time, otherwise known as scaffolding.

The primary underpinning of SDL is that students take responsibility for learning well beyond what is presented by an external body (eg, faculty member, the curriculum). In a more traditional educational setting, an instructor will provide learning objectives, assessments, and resources to help students learn the material. However, in SDL, the learner initiates the process by setting learning objectives, identifying assessments that allow feedback, and identifying resources to help them reach their goals. By taking the lead on their learning, the learner takes responsibility 


\section{American Journal of Pharmaceutical Education 2020; 84 (3) Article 847512.}

for many activities that are traditionally dictated by the instructor, who is now free to facilitate the learning. ${ }^{2}$

The SDL approach is a fundamental shift for an educator because it moves them from being a purveyor of information to assume the role of facilitator of learning, motivator, designer of the learning situation, and often joining the students in earnest as a co-learner as they learn instructional skills (eg, facilitation) and knowledge (eg, context beyond their expertise). ${ }^{3}$ As such, SDL instills a sense of autonomy and mastery in the learner, and a sense of purpose into the educational process. In a well-designed SDL environment, students' motivation increases, as well as their feelings of control, confidence, and belief in themselves. ${ }^{4}$ Most importantly, it supports the unlimited learning potential and creativity of our students.

It is important to differentiate self-directed learning from self-paced learning and self-regulation (Table 1). Self-paced learning is when students have a deadline but complete learning activities at their own pace. Essentially, students are given the autonomy to choose when and for how long they work on various tasks. Self-paced learning does not involve the identification of learning goals or identifying resources to accomplish the goals, which are requirements for SDL. For example, giving students two weeks to read a chapter for class is selfpaced, but because they do not determine what they learn, it is not self-directed. The learning goals and any needed resources are supplied by the instructor.

Self-regulation refers to the process of an individual guiding goal-directed activities over time, that is, acting in their own best self-interest. Self-regulation maximizes the long-term best interest of an individual, resulting in learners controlling their impulses and looking out for their own wellbeing. ${ }^{5}$ This regulation involves modulation of affective, cognitive, and behavioral processes throughout a learning experience to reach a desired level of achievement. ${ }^{6-9}$ Some important difference between self-regulated learning and self-directed learning are that self-regulated learning stems from cognitive psychology while SDL stems from adult education; self-regulation is mainly discussed within the academic environment while SDL usually takes place outside of the traditional classroom; with self-regulation, the task is imposed by the instructor, while in SDL, the student designs the learning environment; finally, self-regulation is a narrower construct than SDL. ${ }^{10}$ For example, a student can demonstrate self-regulation by spending extra time studying less familiar material and selecting appropriate study strategies to do so. However, this does not necessarily require the learner to identify their own goals of what they want to learn because the goals are set by the instructor.

\section{Strategies to Develop Self-Directed Learners}

Before creating educational activities to develop SDL, the instructor must first understand what SDL is and what the key components of the SDL process are. Selfdirected learning can be described as a six-step process: developing goals for study; outlining assessment with respect to how the learner will know when they achieve those goals; identify the structure and sequence of activities; lay out a timeline to complete activities; identify resources to achieve each goal; and locate a mentor/faculty member to provide feedback on the plan.

In addition, developing self-directed learners requires a scaffolded approach in which more self-paced or teacherdirected activities are introduced early on, during didactic instruction, to help students become more self-regulated in their "self-directedness." Over time, as the student moves from the classroom to the experiential setting, control of the learning environment can be shifted from the instructor to the student. This scaffolding may include starting with more self-paced activities and providing guidance to the learner on how to be more self-regulated. Health professions

Table 1. Comparison of Traditional Classroom to Self-Directed Learning, Self-Paced Learning, and Self-Regulated Learning $8,12,25,26$

\begin{tabular}{|c|c|c|c|c|}
\hline & $\begin{array}{l}\text { Traditional } \\
\text { Learning }\end{array}$ & $\begin{array}{l}\text { Self-Directed } \\
\text { Learning }\end{array}$ & $\begin{array}{c}\text { Self- } \\
\text { Paced } \\
\text { Learning }\end{array}$ & $\begin{array}{c}\text { Self- } \\
\text { Regulated } \\
\text { Learning }\end{array}$ \\
\hline $\begin{array}{l}\text { Learner chooses the timing of to-be- } \\
\text { learned material }\end{array}$ & No & Yes & Yes & Yes \\
\hline $\begin{array}{l}\text { Learner chooses order of to-be-learned } \\
\text { material }\end{array}$ & No & Yes & No & Yes \\
\hline Learner must identify own resources & No & Yes & No & Yes \\
\hline Requires student motivation & Yes & Yes & Yes & Yes \\
\hline Fosters Metacognitive Awareness & No & Yes & Some & Yes \\
\hline Typical Environment & Classroom & $\begin{array}{l}\text { Outside of the } \\
\text { Classroom }\end{array}$ & Classroom & Classroom \\
\hline
\end{tabular}




\section{American Journal of Pharmaceutical Education 2020; 84 (3) Article 847512.}

programs may employ several educational components to help develop SDL: flipped classrooms, learning contracts, and minimal-guidance instruction.

A "flipped classroom" can be described as a learning model where students obtain some foundational material on their own, prior to class, and then class time is used to help apply that learned information. ${ }^{11-13}$ An example of a highly structured flipped classroom is team-based learning (TBL). Flipped classrooms have the potential to move students towards self-directed learning. First, students prepare prior to class through faculty-provided materials. This preparation allows students to develop confidence in self-regulation skills (eg, what to focus their time on, selecting appropriate study strategies, self-assessment) and self-pace learning (eg, "I need to get this done before class, but I am free to study when I want and for how long I want"). With the help of the instructor, the targeted content acquired outside of class can be applied, expanded upon, and worked with in such a way to reinforce and deepen learning. This may serve to model and assist the student in the development of the skills needed for future self-direction.

While in some flipped classrooms learning may cease when the class period ends or after completion of some post-lesson homework, learning in a flipped class can be made more self-directed by having students develop a small, individual-learning plan on how they might further explore the course topic. For example, prior to discussing hypertension, students could be given guided questions to use in navigating the most recent hypertension treatment guidelines. Prior to class, students should read the questions and try to answer them through interacting with the guidelines. This can help activate the student's prior knowledge of the topic, introduce them to a reliable resource (eg, clinical guidelines), and help them learn the basics of classifying hypertension and identifying first line therapies. Class time can then be used to apply this knowledge in novel ways. Towards the end of class, students can be asked to develop questions they want to further explore outside of class and devise a learning plan to let the instructor know they went beyond the classroom learning. For example, a student with an interest in pediatric medicine could develop questions and a learning plan focused on the therapeutic guidelines for hypertension in pediatric patients.

In crafting this plan, the student would have to proceed through the six steps of self-directed learning (Table $2)^{2}$ The first step is developing goals for study (ie, "I want to know how to treat hypertension in pediatric patients"). The second step is outlining assessment in terms of how the learner will know they have achieved those goals (ie, "I will provide an executive summary and maybe a flow chart to illustrate understanding of the hypertension guidelines"). Once the goals and measurable outcomes or deliverables are defined, the next step is to identify the structure and sequence of activities ("I will read the current guidelines for adults and see if there is mention of pediatric patients, and then conduct a literature search"). The fourth

Table 2. Steps Involved in Self-Directed Learning

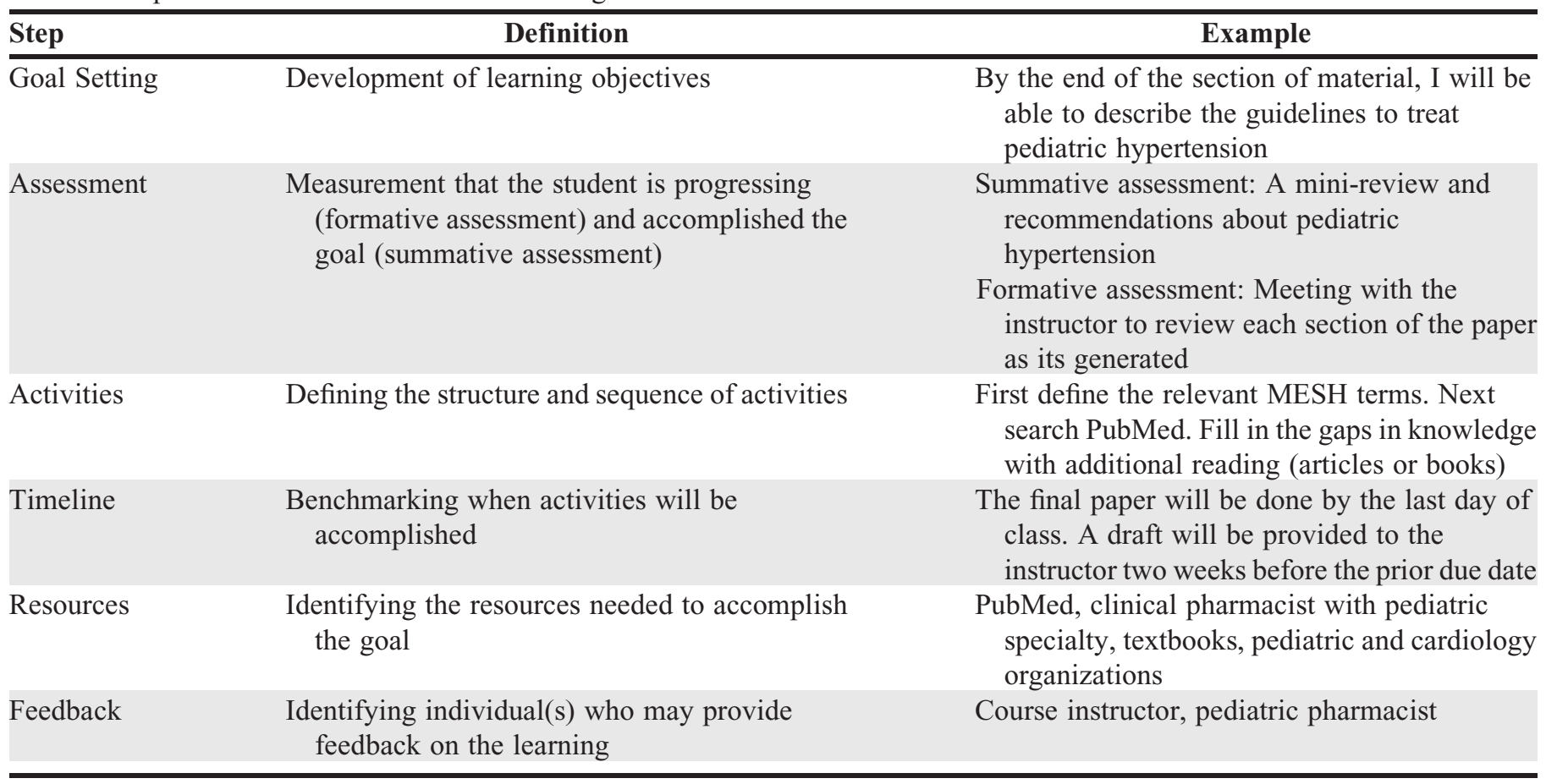




\section{American Journal of Pharmaceutical Education 2020; 84 (3) Article 847512.}

step is to draft a timeline to complete activities ("I will do this before the next class period"), and the fifth step is to identify resources to achieve each goal ("I will need to access current guidelines, UptoDate, PubMed, pediatric cardiology organizations"). Finally, the learner locates a mentor/faculty member to provide him or her with feedback on the plan ("I will ask the cardiology instructor and my former preceptor who specializes in pediatrics for help").

Another method that can be used to help promote SDL is through learning contracts. A learning contract is an agreement between the instructor and student that specifies the work the learner will complete in a given time period. ${ }^{2}$ Learning contracts can be used to keep individuals organized, normalize expectations, and increase communication between the learner and instructor. These contracts consist of five components, similar to that of the SDL process: learning objectives, learning resources and strategies, target date for completion, evidence of accomplishment, and criteria for evaluating. ${ }^{14}$ These can be used within courses, as independent studies, or even to help guide extra- or co-curricular activities.

As an example of effectiveness, one study in bachelor level nurses examined the use of learning contracts in mental health training. ${ }^{15}$ In the qualitative analysis, students reported an increased sense of control over their learning, which was conducive to the autonomy and responsibility of nurses. These contracts also empowered and motivated students. One of the major barriers was time. For instructors, it was more time spent supervising students. For students, it was limited time in a clinical setting to implement and benefit from the learning contract. Other barriers included unattainable goals and instructor anxiety because they were unfamiliar with how to facilitate the self-directed nature.

The last category we will discuss is minimally guided instructional approaches. This approach suggests that people learn best in an unguided or minimally guided environment. Popular formats for minimally guided instructions include problem-based learning (PBL) or inquiry-based learning (IBL). Because of the minimal guidance provided, this type of instruction may foster self-directed learning.

As an example, Lyons and colleagues reviewed some of the literature on the influence of a type of IBL, problem-based learning (PBL), on self-directed learning. ${ }^{16}$ The results of the review were mixed, making conclusions about the effectiveness of this approach difficult to ascertain, though most studies showed that PBL fosters selfdirected learning. Effectiveness may be impacted by group size and how well instructors or students understand self-directed learning. Maastricht University's school of medicine was founded on a PBL framework and has reported the process eroding over time because of administrative, faculty, and student behaviors requiring focused intervention to revitalize the PBL process. ${ }^{17}$ It may be problematic for curriculums using PBL to foster self-directed learning and indicate that care needs to be taken to assure that the quality of the instructional environment is continually maintained. In addition, minimal guidance instruction probably only benefits learners when they have sufficiently high prior knowledge to provide their own guidance. ${ }^{18}$

\section{Assessing Self-Directed Learning}

How do faculty members know they are helping students become more self-directed? Assessing a learner's progress in becoming self-directed is challenging. While faculty members can assess the results of self-direction (acquisition of skills and content), assessing their development of skills to engage in the SDL process is not that straightforward. Unfortunately, there is a lack of literature on how to objectively assess self-directed learning skills because the domains commonly assessed are affective in nature (problem solving, collaboration, communication, self-awareness, innovation and professionalism).

Self-reported measures are the dominant method to assess individual self-direction. In some cases, a standardized tool is used, such as the Self-Directed Learning Readiness Scale ${ }^{19-22}$ or the Oddi Continuing Learning inventory. ${ }^{23}$ These instruments may be more appropriate for assessing readiness for self-direction than an outcome-based measure. Outcomes-based assessment of SDL generally includes more qualitative methods as the focus is about constructing meaning and the personal development of affective domainrelated skills from the experience. Thus, methods may include subjective approaches including reflection, interviews, and observation of behavior. ${ }^{16,24-26}$

\section{Challenges Encountered When Using a Self-Directed Learning Approach}

Educators may encounter challenges when using self-directed learning and these challenges can be classified into a categories: time (eg, SDL may be less "efficient" than direct instruction), acceptance of change, assessment of student learning, motivation, and lack of expertise by the learner. Students who are novice learners in a specific domain may not be equipped to design their own learning goals or know where to find quality information in solving a problem. In some ways, traditional instruction occurs because the instructor has insight to the skills and knowledge a novice may need to develop and knows how to guide learning in a specific domain. To prepare students with the confidence and skills needed to develop into well-rounded health care providers, a foundation of SDL experiences should be strategically 


\section{American Journal of Pharmaceutical Education 2020; 84 (3) Article 847512.}

scaffolded into the didactic curriculum to prepare students for the more robust SDL required during advanced pharmacy practice experiences. In addition, student maturity level and confidence may also play a factor in readiness for SDL, causing skill development to vary between students. ${ }^{27-29}$ To overcome this particular barrier, targeted feedback from the instructor or coach is needed to help students refine and focus learning outcomes throughout the process.

\section{CONCLUSION}

Like many skills, developing self-directed learners takes time and requires faculty members to shift from being the "sage on the stage" to either a "guide on the side" or, ideally, an authentic co-learner. The time dedicated to developing self-directed learners may compete with other job responsibilities or require the reprioritization of other curricular outcomes. Self-direction may also require the learner to have a certain level of maturity and motivation, which may be why self-directed learning comes from the adult education literature. Given the expectation to develop future health care providers that are life-long learners, the benefits associated with shifting even a part of the curriculum to SDL may outweigh the risks.

\section{REFERENCES}

1. Hiemstra R. Self-directed learning: why do most instructors still do it wrong. Int J Self-Directed Learn. 2013;10(1):23-34.

2. Knowles MS. Self-Directed Learning: A Guide for Learners and Teachers. Chicago: Association Press; 1975.

3. Abraham RR, Upadhya S, Ramnarayan K. Self-directed learning. Am J Physiol Adv Physiol Educ. 2005;29(2):135-136.

4. Boyer SL, Edmondson DR, Artis AB, Fleming D. Self-directed learning: a tool for lifelong learning. J Market Educ.

2014;36(1):20-32.

5. Sitzmann T, Ely K. A meta-analysis of self-regulated learning in work-related training and educational attainment: what we know and where we need to go. Psychol Bull. 2011;137(3):421-442.

6. Winne PH. Inherent details in self-regulated learning. Educ

Psychol. 1995;30(4):173-187.

7. Boekaerts M, Maes S, Karoly P. Self-regulation across domains of applied psychology: is there an emerging consensus? Appl Psychol. 2005;54(2):149-154.

8. Karoly P. Mechanisms of self-regulation: a systems view. Ann Rev Psychol. 1993;44(1):23-52.

9. Zimmerman BJ. Becoming a self-regulated learner: which are the key subprocesses? Contemp Educ Psychol. 1986;11(4):307-313.

10. Saks K, Leijen Ä. Distinguishing self-directed and self-regulated learning and measuring them in the e-learning context. Proedia Soc Behav Sci. 2014;112:190-198.
11. DeLozier SJ, Rhodes MG. Flipped classrooms: a review of key ideas and recommendations for practice. Educ Psychol Rev. 2017;29(1):141-151.

12. Persky AM, McLaughlin JE. Troubleshooting the flipped classroom in medical education: common challenges and lessons learned. Med Sci Educ. 2018;28(1):235-241.

13. Lage MJ, Platt GJ, Treglia M. Inverting the classroom: a gateway to creating an inclusive learning environment. $J$ Econ Educ. 2000;31(1):30-43.

14. Galbraith MW, Gilley JW. Using self-directed learning contracts to improve performance and instruction. Perf Instruct $J$. 1984;23(8):9-10.

15. Chien W-t, Chan SW-c, Morrissey J. The use of learning contracts in mental health nursing clinical placement: an action research. Int J Nurse Stud. 2002;39(7):685-694.

16. Sofie MML, Magda J, Remy MJPR. Self-directed learning in problem-based learning and its relationships with self-regulated learning. Educ Psychol Rev. 2008;20(4):411-427.

17. Moust JHC, Berkel HJMv, Schmidt HG. Signs of erosion: reflections on three decades of problem-based learning at Maastricht University. High Educ. 2005;50(4):665-683.

18. Kirschner PA, Sweller J, Clark RE. Why minimal guidance during instruction does not work: an analysis of the failure of constructivist, discovery, problem-based, experiential, and inquirybased teaching. Educ Psychol. 2006;41(2):75-86.

19. Ayyildiz Y, Tarhan L. Development of the self-directed learning skills scale. In J Lifelong Learn. 2015;34(6):663-679.

20. Behar-Horenstein LS, Beck DE, Su Y. An initial validation study of the self-rating scale of self-directed learning for pharmacy education. Am J Pharm Educ. 2018;82(3):280-286.

21. Long HB, Agyekum SK. Guglielmino's self-directed learning readiness scale: a validation study. High Educ. 1983;12(1):77-87.

22. Zhoc KCH, Chen G. Reliability and validity evidence for the Self-Directed Learning Scale (SDLS). Learn Individ Diff.

2016;49:245-250.

23. Oddi LF. Development and validation of an instrument to identify self-directed continuing learners. Adult Educ $Q$. 1986;36(2):97-107.

24. Costa AL, Kallick B. Assessment Strategies for Self-Directed Learning. US: Corwin Press; 2003.

25. Evensen DH, Glenn J, Salisbury-Glennon JD. A qualitative study of six medical students in a problem-based curriculum: toward a situated model of self-regulation. J Educ Psychol.

2001;93(4):659-676.

26. Lloyd-Jones G, Hak T. Self-directed learning and student pragmatism. Adv Health Sci Educ. 2004;9(1):61-73.

27. Baxter Magolda MB. Evolution of a constructivist conceptualization of epistemological reflection. Educ Psychol. 2004;39(1):31-42.

28. Baxter Magolda MB. Three elements of self-authorship. $J$ College Stud Develop. 2008;49(4):269-284.

29. King PM, Baxter Magolda MB. A developmental model of intercultural maturity. J College Stud Develop. 2005;46(6): 571-592. 